\title{
Analysis of drought conditions over major maize producing provinces of South Africa
}

\author{
Omolola M. Adisa ${ }^{\mathrm{a}, \dagger}$, Joel O. Botal ${ }^{\mathrm{a}, \mathrm{b}, \mathrm{c}}$, Abiodun M. AdeOla ${ }^{\mathrm{b}, \mathrm{d}}$, Christina M. BotaI ${ }^{\mathrm{b}}$, Abubeker Hassen ${ }^{\mathrm{e}}$, \\ Daniel Darkey ${ }^{\mathrm{a}}$, Eyob Tesfamariam ${ }^{\mathrm{f}}$, Abidemi T. Adisa ${ }^{\mathrm{g}}$ and Alex F. Adisa ${ }^{\mathrm{h}}$

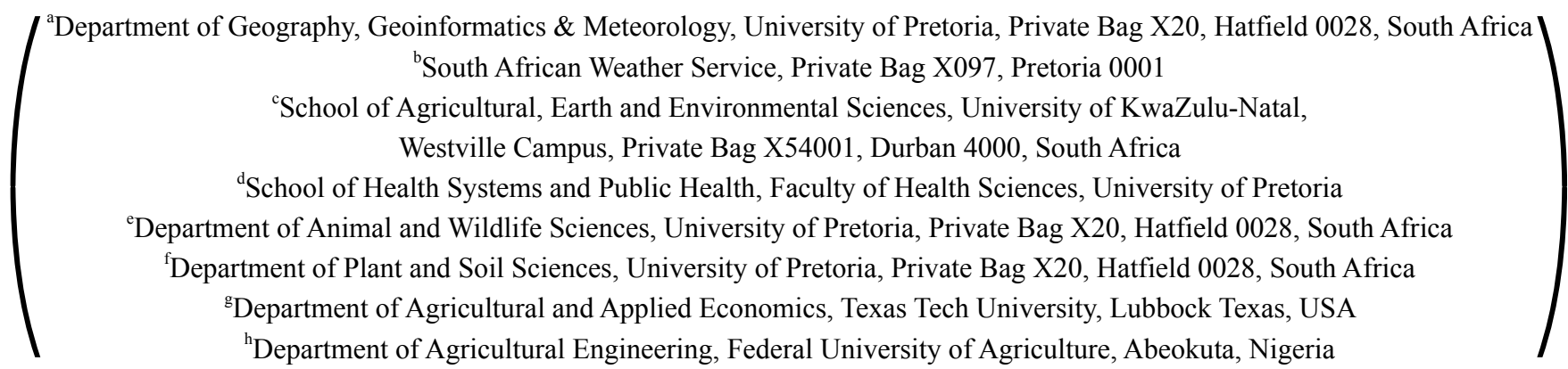

\begin{abstract}
In this study, two commonly used drought indices; the Standardized Precipitation Index (SPI) and Standardized Precipitation Evapotranspiration Index (SPEI), were analyzed in order to understand the impacts of drought on maize yield over four main maize production provinces of South Africa. The drought was characterized using three Drought Monitoring Indicators (DMI) i.e., the Drought Duration (DD), Drought Severity (DS), and Consecutive Drought Months (CDM). The results indicate that maize yield is significantly affected by drought across the entire study area, although the impacts are localized. A comparison between the SPI and SPEI with maize yield suggests that the SPEI is more correlated and sensitive to maize yield than the SPI. The maize yield is particularly most sensitive to the 3-month SPEI. The 3-month accumulation period coincides with maize growing season $(r=0.59 ; p<0.05)$. The analyzed results illustrate that drought affects maize yield by up to $35 \%$ across the study area. Additionally, results depict inherent spatial patterns of DMIs demonstrating that there are differentiated drought impacts across the maize production areas. The results suggest that management strategies that allow for optimal water use within the first 1- and 3-month periods would be most effective for sustainable maize production within the study area. This research study contributes towards a deeper understanding of the characteristics of drought and their impacts on maize crop production. Such knowledge is important in e.g., the formulation of drought monitoring and prediction strategies including drought early warning systems.
\end{abstract}

Key words: Agriculture, Climate, Drought, Maize, Yield

\section{Introduction}

Drought is considered as a slow and creeping recurring natural phenomenon (Wilhite, 2000). The effects of drought are manifested in many economic as well as social sectors. In agricultural sector, drought is considered as one of the major cause that leads to crop yield failure, particularly in both rain-fed and irrigated agro-ecosystems (Grayson, 2013; Zhang and Zhang, 2016). Recently (2016-2018), South Africa has experienced prolonged drought (Botai et al., 2016; 2017) that has affected both agricultural production and water resources, with the impacts already propagated into socio-economic. Due to persistent and widespread severe drought impacts in the country, robust emphasis on understanding the impacts this natural hazard as on key economic sectors is warranted. Research studies on

Received; December 11, 2018

Accepted; May 2, 2019

†Corresponding Author: u13387562@tuks.co.za

DOI: 10.2480/agrmet.D-18-00049 drought issues include understanding drought characteristics, (e.g. the onset, duration, intensity, magnitude, spatial extent, etc.). Such information is essentially important for better preparedness and proper management of key socio-economic sectors such as water and agriculture, which promote water quality and food security at regional as well as national level (Kurniasih and Impron, 2017).

Drought indices such as the Palmer Drought Severity Index (PDSI) (Palmer, 1968), the Crop Moisture Index (CMI) (Palmer, 1968), the Soil Moisture Drought Index (SMDI) (Hollinger, et al., 1993), the Standardized Precipitation Index (SPI) (McKee et al., 1993), the Standardized Precipitation Evapotranspiration Index (SPEI) (Vicente-Serrano et al., 2010), the Effective Drought Index (EDI) (Byun and Wilhite, 1999), the Agricultural Reference Index for Drought (ARID) (Woli et al., 2013), and the Vegetation Health Index (VHI) (Dalezios et al., 2014) are widely used by various agencies and researchers as tools for drought assessment, monitoring, analysis and alert, with the aim being to derive effective early warning drought monitoring systems for detecting and responding to potential future drought risks. Most 
of these indices are selected based on various factors that include the nature of the hydro-climatology of the region, the type of drought considered, the purpose of the study and the available data (Morid et al., 2006).

The SPI is the most commonly used drought index and well recommended by the World Meteorological Organization (Potop et al., 2012; Chen et al., 2013), as it is flexible in monitoring all the three types of drought (e.g. meteorological, agricultural, and hydrological). This index is primarily based on precipitation, whereas, its counterpart, the SPEI requires both precipitation and potential evapotranspiration information (PET), which is often computed from the minimum and maximum temperatures. Both the SPI and SPEI drought indices have the capability to detect and depict drought on a multi-temporal scales. In particular, the SPI and SPEI at 1-, 3-, and 6- accumulation months are often used to assess meteorological to agricultural drought impacts, whereas the 12 months and above (up to 24) are ideal for the hydrological socio-economic impacts, respectively (Morid et al., 2006; Potop et al., 2014).

A number of research studies analyzing and monitoring drought cases based on the SPI and SPEI drought indices have being reported in the literature (e.g., Chen et al., 2016; Botai et al., 2016; Meroni et al., 2017; Botai et al., 2017). Other studies have demonstrated the application of SPI or SPEI or a combination of both and other drought indices as tools for measuring and monitoring drought and its impacts on agricultural production (Ceglar et al., 2012; Mansouri et al., 2013; Dutta et al., 2015; Chen et al., 2016; Zipper et al., 2016; Kurniasih and Impron, 2017). In South Africa, most of the research studies have focused on drought assessment and monitoring (e.g. Edossa et al., 2014; Rouault and Richard, 2003; Botai et al., 2016 and 2017) with no-direct link to a specific type of drought. The only study that related drought to agriculture was reported by Masupha and Moeletsi (2017), although the authors considered the SPEI-1, which often reflects short-term conditions of soil moisture and crop stress.

The recent droughts (e.g. 2016-2018) that have affected at least five South African provinces have renewed the need for more research on the drought impacts and the need for effective planning to assist in mitigating feasible inherent effects of drought. Maize production is the most important grain crop in South Africa, accounting to approximately $46.2 \%$ of the gross value of field crops (DAFF, 2017). Drought persistence has the potential to create significant and devastating maize production challenges, leading to economic and financial difficulties for agricultural producers. To alleviate farm revenue losses and support government policy-makers on drought issues, there's a need to qualitatively evaluate the impacts of drought on maize production. For this purpose, the aim of this study is to investigate the impacts and the characteristics of drought in major maize producing provinces of South Africa based on the SPI and SPEI 1-, 3-, 6- and 12-month timescales during the main crop growth stages of October to April. In particular, the specific objectives of the current study are defined as follows: 1) to characterize the drought conditions using monitoring indicators (i.e., the drought duration, severity and magnitude), 2) to determine the most significant index and timescale for which marginal maize yield is sensitive to, and 3) to describe the association of drought monitoring indicators to spatiotemporal contrast of maize production.

\section{Materials and methods}

\subsection{Study area}

The study area includes the north-eastern part of South Africa between longitude $22^{\circ} \mathrm{E}$ to $33^{\circ} \mathrm{E}$ and latitude $-32^{\circ} \mathrm{S}$ to $-24^{\circ} \mathrm{S}$. It covers the KwaZulu-Natal (KZN), Free State (FS), Mpumalanga (MP) and North West (NW) provinces (see Fig. 1). The FS, MP and NW provinces fall within regions that receive less than $600 \mathrm{~mm}$ of rainfall per year. In 2017 season, these provinces accounted for about $87 \%$ of the total maize produced in South Africa. In particular, MP province accounted for $20 \%$, while NW, FS, and KZN provinces accounted for $19 \%, 44 \%$ and $4 \%$ of total maize production respectively. The FS and NW provinces contributed about $78 \%$ of the total white maize produced in 2017 while the FS and MP produced about $67 \%$ of the total yellow maize harvested. Most crops including maize are grown between October and March period. The FS province is characterized by chilly winters (ranging from a cold $1^{\circ} \mathrm{C}$ to mild $17^{\circ} \mathrm{C}$ ), plenty of sunshine $\left(15^{\circ} \mathrm{C}\right.$ to $\left.32^{\circ} \mathrm{C}\right)$ and summer rains $(500 \mathrm{~mm}-600 \mathrm{~mm}$ annually). Located in the north-eastern part of the country, is the Vaal irrigated area which nourishes the small assortment of farming towns. In NW province there is almost a year-round sunshine, with an average rainfall of 300 to $600 \mathrm{~mm}$ annually. The summer temperature ranges from $22^{\circ} \mathrm{C}$ to $34^{\circ} \mathrm{C}$. The NW province is characterized by dry, sunny days and chilly nights during winter $\left(2^{\circ} \mathrm{C}\right.$ to $\left.20^{\circ} \mathrm{C}\right)$ season. The temperature in $\mathrm{KZN}$ ranges between $23^{\circ} \mathrm{C}$ to $33^{\circ} \mathrm{C}$ in summer (December-February), and $16^{\circ} \mathrm{C}$ to $25^{\circ} \mathrm{C}$ during winter (June-August). The province is characterized by long, hot summers with average annual rainfall ranging between $500 \mathrm{~mm}$ and $900 \mathrm{~mm}$, and mild winters. Furthermore, the western part of the MP province is much colder during winter and hotter during summer than the other parts of the province. The average annual temperature is about $19^{\circ} \mathrm{C}$ and rainfall is between $500 \mathrm{~mm}$ and $800 \mathrm{~mm}$ annually. The time series of total monthly precipitation (PRE), average

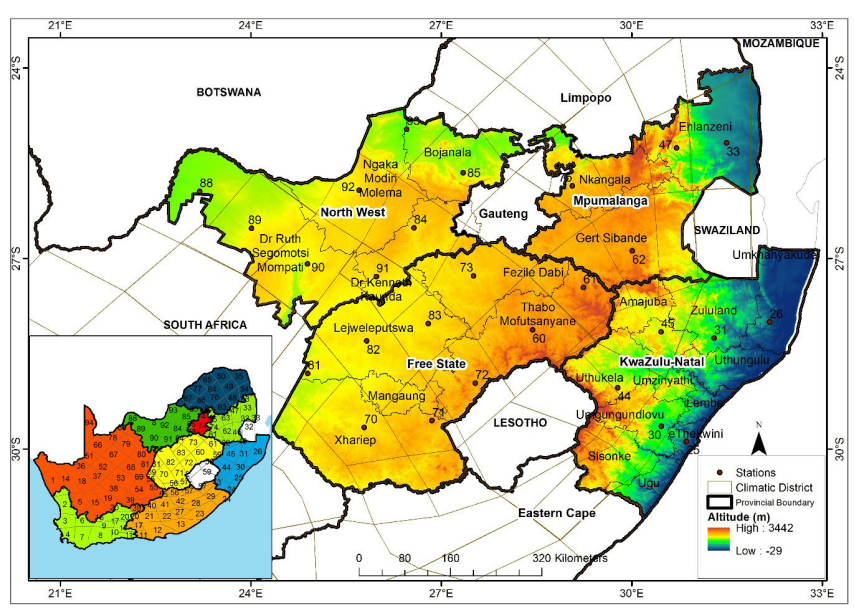

Fig. 1. Study area showing elevation, South African Weather Service climatic districts and centroids of the climatic districts in the proximity of stations with provincial borders superimposed. 


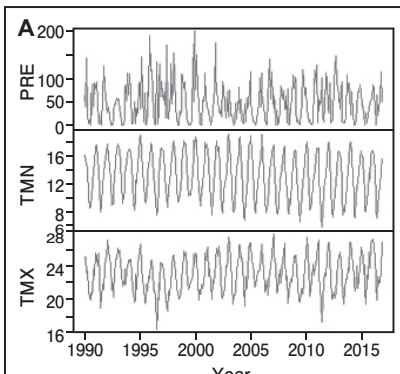

Year

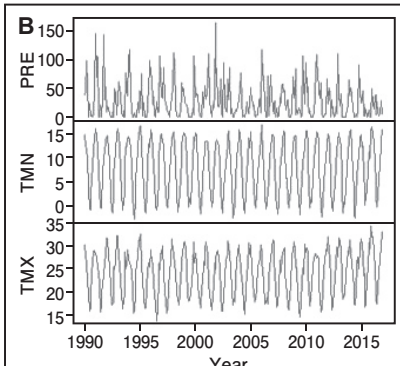

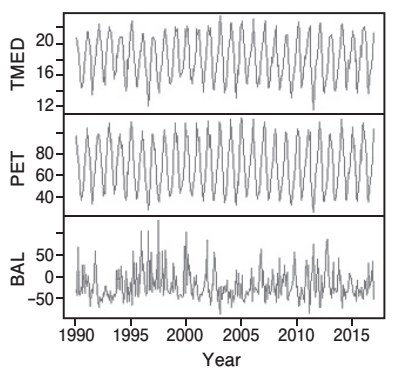

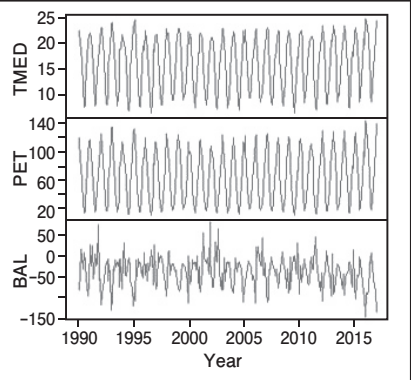

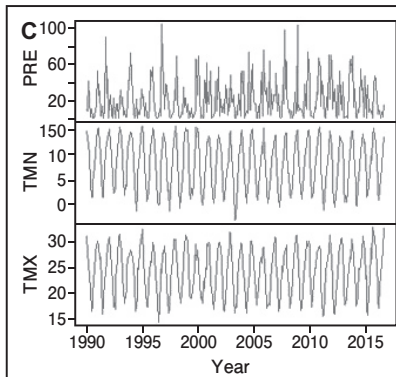
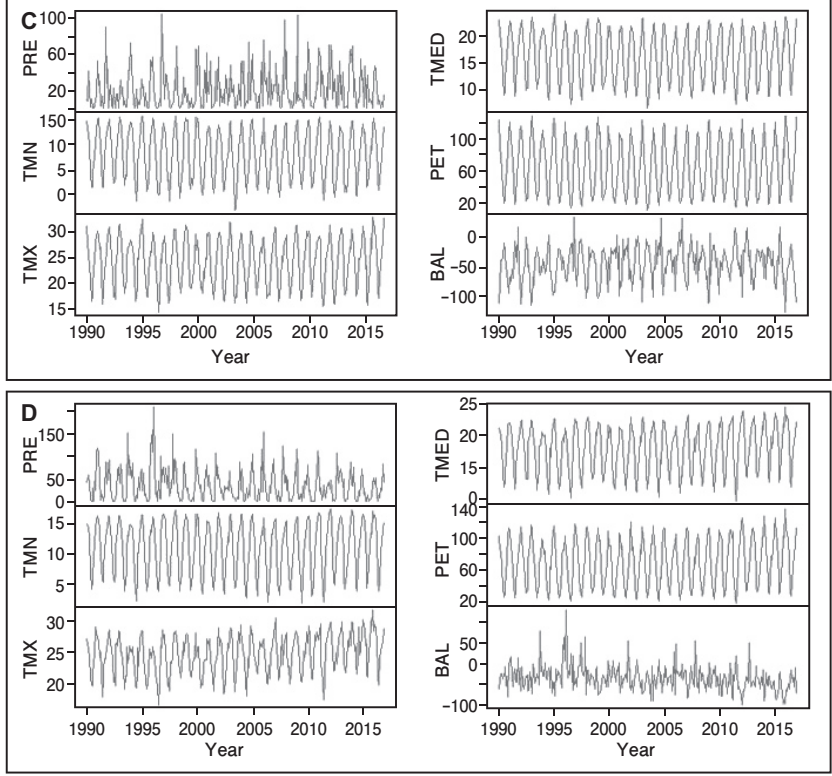

Fig. 2. The time series of total monthly precipitation (PRE) (mm), average monthly maximum (TMX), minimum (TMN) and mean (TMED temperature $\left({ }^{\circ} \mathrm{C}\right)$, potential evapotranspiration (PET) $(\mathrm{mm} / \mathrm{month})$ and water deficit (BAL) (mm) from 1990-2015 in A: Mpumalanga, B: Free State, C: North West and D: KwaZulu Natal provinces.

monthly maximum (TMX), minimum (TMN) and mean (TMED) temperature, potential evapotranspiration (PET) and water deficit (BAL) over each province is given in Fig. 2.

\subsection{Materials}

Pre-processed gridded historical observations of daily precipitation, minimum and maximum temperature from 27 ground stations ( 6 in KZN, 4 in MP, 8 in NW and 9 in FS) (see Fig. 1) spanning from 1990 to 2015, over the study area, were acquired from the South African Weather Service (SAWS). The maize production data sets in tons from 1990 to 2015 were obtained from the Abstract of Agricultural Statistics compiled by the Department of Agriculture, Forestry, and Fisheries of South Africa. The abstract document contains important information on inter alia, field crops, horticulture, livestock, vital indicators and the total land area in hectares (ha) used for maize production among others.

\subsection{Methods}

\subsubsection{Analysis of drought by SPI and SPEI}

In this contribution, we investigated the characteristics of drought over the major maize producing provinces of South Africa using the SPI and SPEI at 1-, 3-, 6-, and 12-month timescales. The advantages of using SPI and SPEI are premised on the principle of parsimony and their ability to quantify the magnitude, duration, and extent of droughts independently of the local climatic conditions and less data intensive. Both the SPI and SPEI at 1-, 3-, 6- and 12-month timescales were computed using the SPEI package in R software (Beguería and Vicente-Serrano, 2013; Vicente-Serrano et al., 2015). The SPI is calculated by fitting a gamma distribution to a precipitation time series (McKee et al., 1993). On the other hand, to compute the SPEI, the computation of "climatic water balance"; the difference between total monthly precipitation and reference evapotranspiration $\left(\mathrm{PRE}-\mathrm{PET}_{0}\right)$, rather than precipitation (PRE) as the input in the case of SPI is required. Although, the Penman-Monteith (PM) method (Allen et al., 1998) has been adopted by the International Commission for Irrigation (ICID), the Food and Agriculture Organization of the United Nations (FAO), and the American Society of Civil Engineers (ASCE) as the standard procedure for computing PET, the Thornthwaite (1948) equation was adopted for this research. The Thornthwaite equation requires only mean daily temperature and latitude of the site rather than the extensive data requirement of the PM equation (Solar radiation, relative humidity, wind speed and temperature) which are in most case not routinely measured at many conventional meteorological stations and long-term records of these variables are lacking. In this study, drought was characterized based on the classification summarized in Table 1. A drought event begins when the SPI or SPEI reaches a value of -1.0 or less and ends when SPI or SPEI becomes positive. It has been determined that SPI or SPEI is in normal, moderate, severe and extreme drought condition at $65 \%, 10 \%, 5 \%$ and $2 \%$ of the time respectively. In this study, it is considered that all the negative values were related to dry conditions. Hence, drought

Table 1. SPI and SPEI categories of drought.

\begin{tabular}{ccc}
\hline SPI/SPEI & Moisture category & Frequency $(\%)$ \\
\hline$\geq 2.0$ & Extreme Wet & 2 \\
1.50 to 1.99 & Severe Wet & 6 \\
1.49 to 1.00 & Moderate Wet & 10 \\
0.99 to -0.99 & Normal & 65 \\
-1.00 to -1.49 & Moderate Drought & 10 \\
-1.5 to -1.99 & Severe Drought & 5 \\
$\leq-2.00$ & Extreme Drought & 2 \\
\hline
\end{tabular}


duration (DD), is defined as the longest period of consecutive months with the values $<0$. On the other hand, consecutive drought month (CDM) also referred to as drought magnitude is defined as the sum of the index values while drought severity (DS) is defined as the number of months with values $<0$ during the maize growing period.

\subsubsection{Trend Analysis}

Trend analysis was performed to determine if there exists significant variation in the datasets over the period of study. The analysis was performed by using the rank-based Mann-Kendall (MK) trend test. Before the MK test was applied, the effect of autocorrelation of data series was firstly removed by applying the trend-free pre-whitening procedure (Yue et al., 2002). The magnitude of the trends was quantified using the Theil-Sen estimator. To compute the trends as well as the Theil-Sen estimator, the regional Kendall test ( $\mathrm{rkt}$ ) package in $\mathrm{R}$ software was used (Marchetto, 2017).

\subsubsection{Statistical model fitting and spatial analysis}

Correlation analysis was used to assess the relationship between the SPI, SPEI and maize yield at different timescales. Since maize is grown in the summer period of the year, only the SPI and SPEI values, calculated from October (maize sowing) until April (maize ripening) have been used in the analysis for each of the four provinces. The estimate yield per unit area was derived by dividing total cultivated area by total production in each province. The slope, the adjusted coefficient of determination $\left(\mathrm{R}^{2}\right)$, and the $p$-values were used to evaluate the relationship between the drought indices and maize yield. For each province, the best relationship was defined as the timing (i.e. the month of the growing season) and timescale (i.e. drought duration) combination with the highest adjusted $\mathrm{R}^{2}$ (Vicente-Serrano et al., 2012). Spatial distribution of SPI, SPEI, DD, DS, CDM, the coefficient of variation (CV), trend and $\mathrm{p}$-values over each of the province were generated by interpolation from the point measuring stations using the inverse-distance-weighted (IDW) algorithm in ArcGIS desktop software (Rhee et al., 2008; Ali et al., 2011; Vasiliades and Loukas, 2013; Chen et al., 2017).

\section{Results}

\subsection{Contrasts of maize yield across the study area}

Over the 26 years under investigation, a total of 216,767 million tons of maize was produced across the study area. The highest maize production was recorded in the FS province with about 90,019 million tons $(41.5 \%)$, followed by the NW with 60,838 million tons $(28.1 \%)$, MP produced 55,823 million tons $(25.8 \%)$ and a total of 10,087 million tons $(4.6 \%)$ was produced in KZN. The analysis revealed that all four provinces experienced a major decline in the production of maize during 1991 and it's significant at $p$-value $=0.003$ (Fig. 3). On the other hand, higher maize production was recorded between 2012 and 2013 in KZN, MP (2012) and FS (2013). The NW province exhibited high maize production in 1993. As shown in Table 2, the highest, lowest and mean maize production in FS is given as 6,247 million, 0,850 million and 3,462 million tons respectively. In KZN the highest maize produced was about 0,599 million tons, lowest of about 0,237 million tons with a mean of 0,388
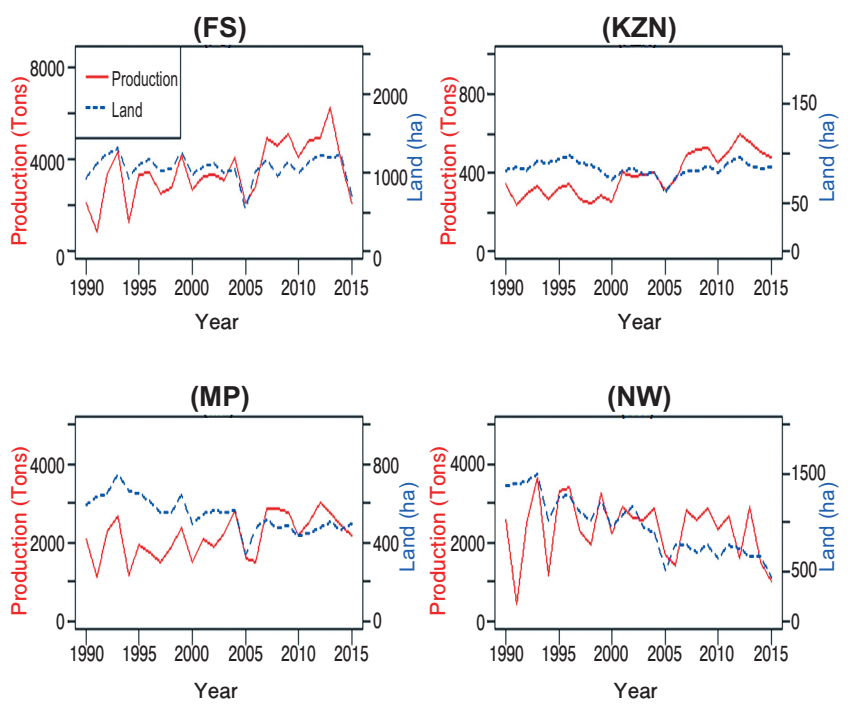

Fig. 3. Plot of time series of maize production (tons) on the left $y$-axis (solid line) and time series of cultivated land for maize (ha) (right y-axis) (dashed line) from 1990-2015 in FS: Free State, KZN: KwaZulu-Natal, MP: Mpumalanga and NW: North West provinces.

Table 2. Statistics of maize production million (tons) and coefficient of variation of maize yield across the four provinces.

\begin{tabular}{lcccc}
\hline Statistics/Province & $\begin{array}{c}\text { Free } \\
\text { State }\end{array}$ & KwaZulu-Natal & Mpumalanga & $\begin{array}{c}\text { North } \\
\text { West }\end{array}$ \\
\hline Minimum & 850 & 237 & 1092 & 404 \\
1st Quartile & 2711 & 299 & 1766 & 1748 \\
Median & 3326 & 372 & 2182 & 2571 \\
Mean & 3462 & 388 & 2147 & 2340 \\
3rd Quartile & 4300 & 487 & 2636 & 2867 \\
Maximum & 6247 & 599 & 3005 & 3635 \\
CV (Yield) & 0.305 & 0.265 & 0.316 & 0.348 \\
\hline
\end{tabular}

million tons while in MP the highest production was 3,005 million tons with lowest of about 1,092 million tons and mean 2,147 million tons. Similarly, the highest production in NW was 3,635 million tons, lowest of 0,404 million tons and mean of 2,340 million tons over the period of study.

\subsection{Spatiotemporal variability of agrometeorological parameters and drought indices across the study area}

A declining trend was observed for precipitation during the critical period of maize phenology across all the provinces. The results revealed that $97 \%$ (26) of the stations had decreasing precipitation during the main maize growth stages ( -1.6 to $-28.5 \mathrm{~mm} \cdot$ decade $\left.^{-1}\right)$. About 15 out of 27 stations exhibited a decreasing trend in rainfall amount $(p<0.05)$. Five of these stations $(84,85,90,91$ and 92) are located in NW, 4 (60, 71, 72 and 83 ) in FS, $3(25,30$ and 40$)$ in KZN and 2 (33 and 62) in MP. The mean temperature increased by $0.14 \pm 0.05^{\circ} \mathrm{C} \cdot$ decade $^{-1}$ over the entire stations in the study area, during the maize growing period (October to April), with $97 \%$ of the stations showing significant warming trends $(p<0.05)$. On the other 
hand, the decline in PET is observed in over $95 \%$ of the stations during the main maize growing period $(p<0.05)$. Positive values of the water balance (BAL) are observed in the month of December and January, indicating that the two months receive the largest rainfall months and are relatively moist.

The long-term spatially-averaged variation of the SPI and SPEI values 1-, 3-, 6- and 12-month periods across the main maize producing province are presented in Figs. 4, 5, 6 and 7. Only selected SPI and SPEI figures (for MP and FS) are presented here, the rest of the figures are provided as supplementary files. Homogeneity test of the SPI and SPEI values revealed significant differences between the two indices particularly the SPI/SPEI calculated at 3- to 12-month timescales. The correlation between the SPI and SPEI varies significantly across the different series. In particular, there is high correlation between the SPI and SPEI series within similar timescales (e.g. SPI-1: SPEI-1 (0.97), SPI-3: SPEI-3 (0.83), SPI-6: SPEI-6 (0.77), SPI-12: SPEI-12 (0.69)).

As indicated from the averaged SPI and SPEI across each province (Figs. 4, 5, 6 and 7), notable years of droughts include 1991/92, 1994/95, 2002/03, 2004/05, 2006/07, 2008/09, $2009 / 10,2011 / 12$ and $2014 / 15$. Using the drought category in Table 1, 1991/92 and 2015/16 seasons are detected as the worst drought periods, reaching severe to extreme conditions. These drought epochs were generally reported to have negative impacts on livestock and crops (Vogel et al., 2000).

Furthermore, the results indicate that there were moderate to extreme drought conditions during the maize growing period (October to April) across all the four provinces, but with inherent variation in the drought duration and severity. Moderate drought conditions dominated in MP, throughout the period. Severe drought occurred during 1991/92 and 2015/16, probably
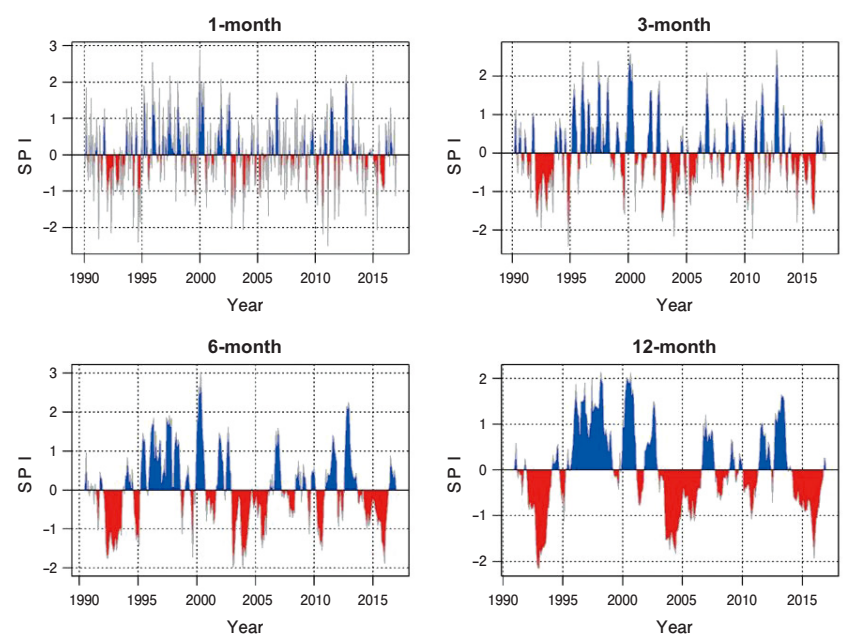

Fig. 4. Drought indices quantified by the SPI in different timescale 1-, 3-, 6- and 12-month calculated using averages over the 4 stations in Mpumalanga province.
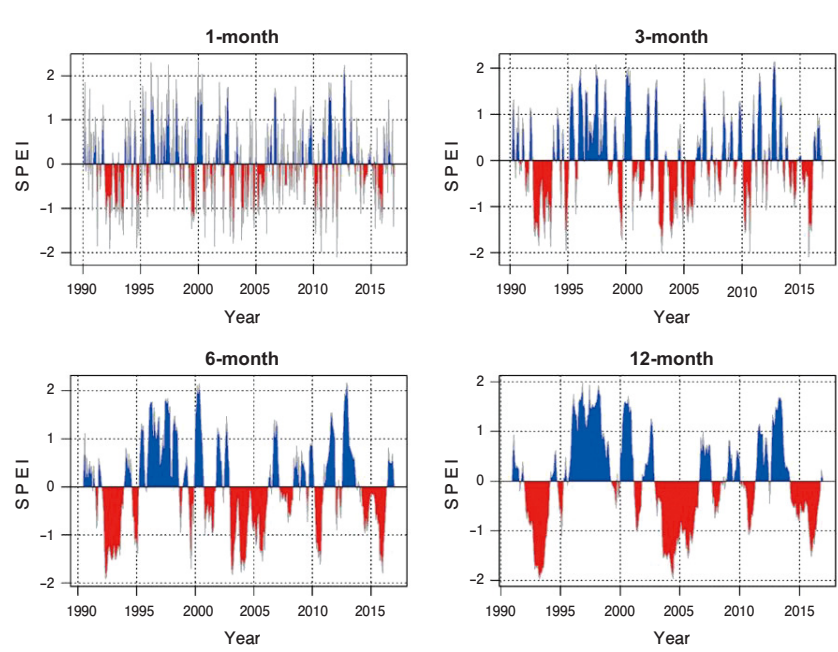

Fig. 5. Drought indices quantified by the SPEI in different timescale 1-, 3-, 6- and 12-month calculated using the averages over the 4 stations in Mpumalanga province.
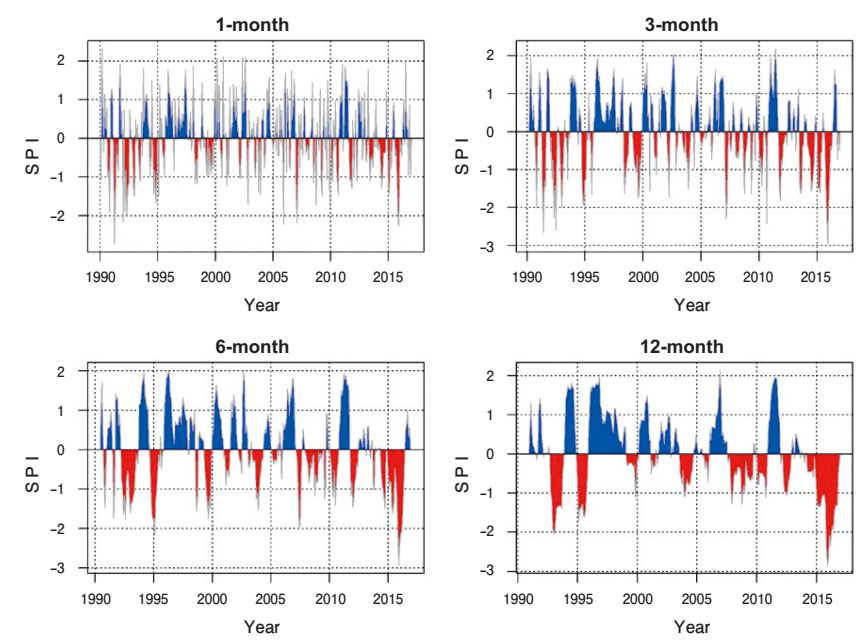

Fig. 6. Drought indices quantified by the SPI in different timescale 1-, 3-, 6- and 12-month calculated using averages over the 9 stations in Free State province.
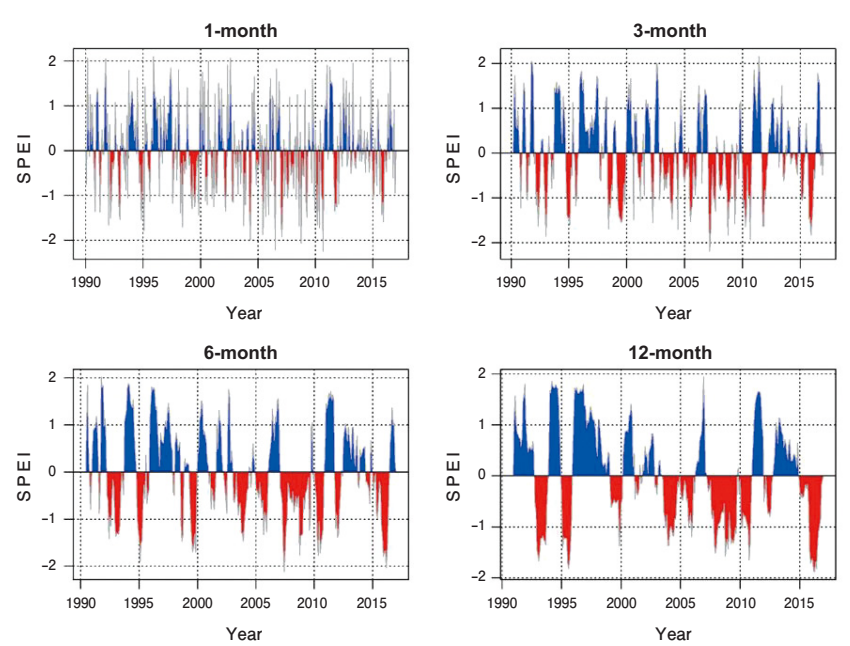

Fig. 7. Drought indices quantified by the SPEI in different timescale 1-, 3-, 6- and 12-month using the averages over 9 stations in Free State province. 
leading to widespread loss of livestock and summer agricultural production (Vogel et al., 2000). Furthermore, as shown by the 1-month drought period of the SPEI, moderate droughts are noticed with high frequency during the vegetative stage, considering planting dates as October across all the provinces. However, the moderate drought during the vegetative stage is more frequent in FS while NW province experiences more frequent extreme drought conditions $(-1.00$ to -1.49$)$ during the vegetative stages, with a severe drought category in 1991/92 and 2014/15 (see supplementary information). On the other hand, the results depict severe drought conditions with high frequency and longer duration during the reproductive stages (3-month) in FS. The KZN province experienced moderate to severe drought in all the drought years identified, reaching an extreme drought condition category in 2015/16.

The major drought years were confirmed by the breakpoints (Fig. 8) detected in SPI and SPEI time series. The horizontal
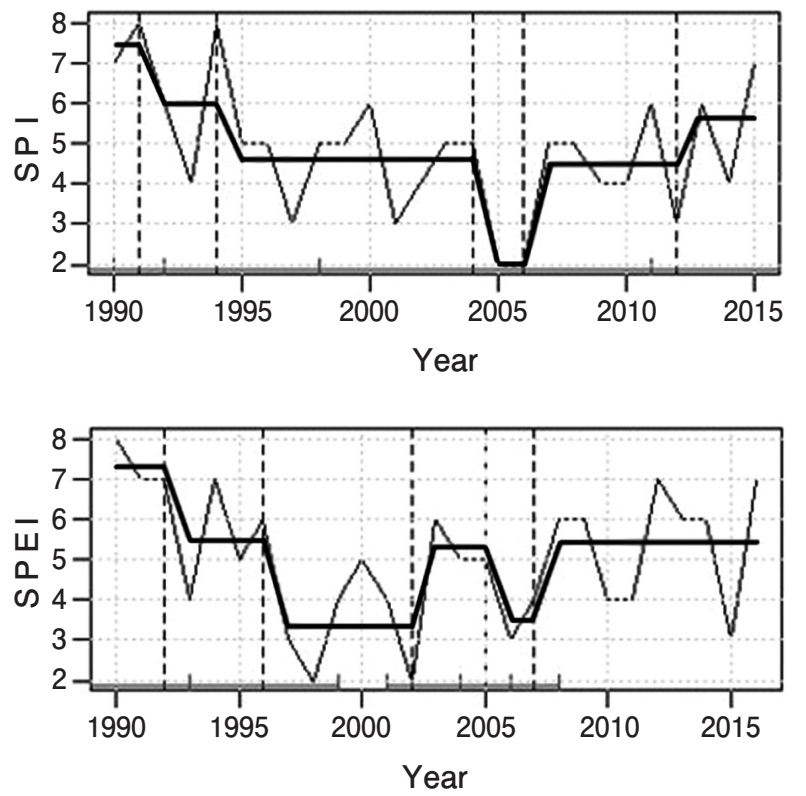

Fig. 8. Breakpoints in SPI and SPEI time series showing the years detected with breakpoints in tick dotted lines. thick and narrow lines represent the values and the trends of the SPI and SPEI respectively, while the vertical tick dotted lines are the breakpoints (significant change points in the time series). In particular, based on the SPI analysis major droughts occurred in 1991/92, 1994/95, 2004/05, 2006/07 and 2012/13. Based on the SPEI analysis, a major drought occurred in 1992/93, 1996/97, 2002/03, 2005/06 and 2007/08. These results confirm findings reported in the previous studies (e.g. Vogel et al., 2000; Rouault and Richard, 2003), indicating that the indices are able to detect periods of significant droughts.

\subsection{Spatial variability of drought conditions across the study area}

In this study, drought conditions across the NW, FS, KZN and MP provinces were characterized based on DMIs such as DD, DS as well as CDM. Statistical parameters such as the mean, the coefficient of variation, and trends of the DMIs were derived from the SPI and SPEI time series. However, for easy readership, only the results for the SPI-3 and SPEI-3 which have higher correlations with maize yield as shown in Table 3 are given. The results for the DD, DS and CDM derived from the SPI-3 and SPEI 3-month are depicted in Fig. 9. As shown in Fig. 9, DD, mean values range between 4 and 6 months across the provinces. The mean of the DD is minimum towards the west-northern part of the NW province (SPI-3) and parts of the FS province (SPEI-3) and increases across the study region, reaching its maximum in regions of MP province (SPI-3) and FS (SPEI-3).

Additionally, the mean values in the DS are lowest in the central region of MP for both SPI-3 and SPEI-3 and maximum in the FS province. On the other hand, the mean CDM values range between 2 and 4 months. Few parts of the MP province depict higher mean for SPI-3 while higher CDM mean is evident in the northern areas of FS province for SPEI-3. The results indicate that drought is more severe in both FS and NW provinces with longer duration in FS. While the drought conditions seem to be less severe in MP province, these conditions exhibit generally persistent characteristics across the province. Given that the SPI-3 and SPEI-3 values correspond to the reproductive stages of maize (averaged December-January) from silking to grain-filling from 61st to 90th day, these drought conditions will, therefore,

Table 3. Correlation coefficients of the SPI and SPEI 1-, 3-, 6- and 12 months series (October to April), p-values and the standardized maize yield in major four maize producing provinces of South Africa from 1990-2015.

\begin{tabular}{ccccccccc}
\hline & \multicolumn{7}{c}{ SPI } \\
\hline Province & SPI-1 & $p$-value & SPI-3 & $p$-value & SPI-6 & $p$-value & SPI-12 & $p$-value \\
\hline KZN & 0.58 & 0.038 & 0.67 & 0.014 & 0.41 & 0.067 & 0.18 & 0.517 \\
MP & 0.53 & 0.044 & 0.56 & 0.032 & 0.32 & 0.132 & 0.21 & 0.445 \\
FS & 0.34 & 0.167 & 0.51 & 0.051 & 0.29 & 0.217 & 0.27 & 0.267 \\
NW & 0.48 & 0.101 & 0.53 & 0.045 & 0.33 & 0.093 & 0.26 & 0.189 \\
\hline & & & & SPEI & & & & \\
\hline Province & SPEI-1 & $p$-value & SPEI-3 & $p$-value & SPEI-6 & $p$-value & SPEI-12 & $p$-value \\
\hline KZN & 0.43 & 0.081 & 0.47 & 0.049 & 0.39 & 0.053 & 0.20 & 0.523 \\
MP & 0.52 & 0.049 & 0.58 & 0.041 & 0.42 & 0.062 & 0.22 & 0.334 \\
FS & 0.60 & 0.041 & 0.62 & 0.035 & 0.56 & 0.047 & 0.31 & 0.114 \\
NW & 0.59 & 0.026 & 0.69 & 0.011 & 0.53 & 0.058 & 0.32 & 0.105 \\
\hline
\end{tabular}


have a huge negative impact on the overall maize production. Note that the study area comprises of the main maize producing areas. These severe and persistent drought conditions inherently threaten the economy and the food security of the country.

The spatial contrasts of the CV results derived from the SPI-3 and SPEI-3 time series are illustrated in Fig. 10. Based on the SPI-3 analysis, the NW province depicts less variability in DD. Similar results are observed for DD derived from the SPEI-3, although few regions in the FS depict maximum $\mathrm{CV}$ values $(\sim 40 \%)$. The $\mathrm{CV}$ values derived from the SPI-3 time series exhibit subtle variation mostly in KZN and highly dispersed in the FS province. For SPEI-3 analysis, the $\mathrm{CV}$ values in DS range between $\sim 28 \%$ (mostly in KZN) and $\sim 40 \%$ (mostly in FS and MP). Based on both the SPI-3 and SPEI-3 time series analysis, vast majority of the study area depicts variations of $\mathrm{CV}$ values in CDM, with maximum values of $\sim 55 \%$ and $\sim 54 \%$ for SPI-3 and SPEI-3, respectively.

The results of spatial-temporal trends in DD, DS and CDM, calculated from SPI- and SPEI- 3-month timescales are depicted in Fig. 11 and their significance (p-values) shown in Fig. 12. Similar trend pattern in DD is observed for both SPI-3 and SPEI-3. In particular, the trends in DD range between -0.05 and 0.04 for the SPI-3 and -0.05 and 0.04 for the SPEI- 3 time series. Subtle negative trends in the DD are observed mainly in the KZN province for both SPI-3 and SPEI-3. On the other hand, trivial positive trends are observed in the DS over large parts of the NW, FS, and some regions in the south-western parts of the MP province. As shown in Fig. 11, no detectable trends in CDM are observed for both SPI-3 and SPEI-3 time series, across the study area, except for a small region in the NW province that depicts subtle negative trends with a minimum of $-0.02 \mathrm{month} /$ year. Overall, the derived trends for the drought indicators across the selected timescales are mostly found to be statistically insignificant at 0.05 . However, a fraction of trends in DS are found to be statistically significant in NW and KZN (see Fig. 11).

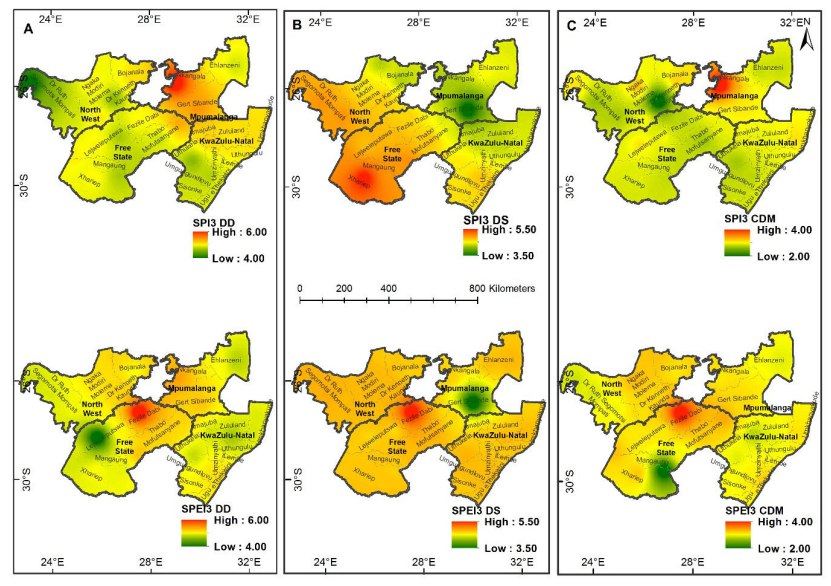

Fig. 9. Spatial contrasts of the mean DMIs derived from SPI-3 (top) and SPEI-3 (bottom): Panel A corresponds to DD while B and C correspond to DS and CDM.

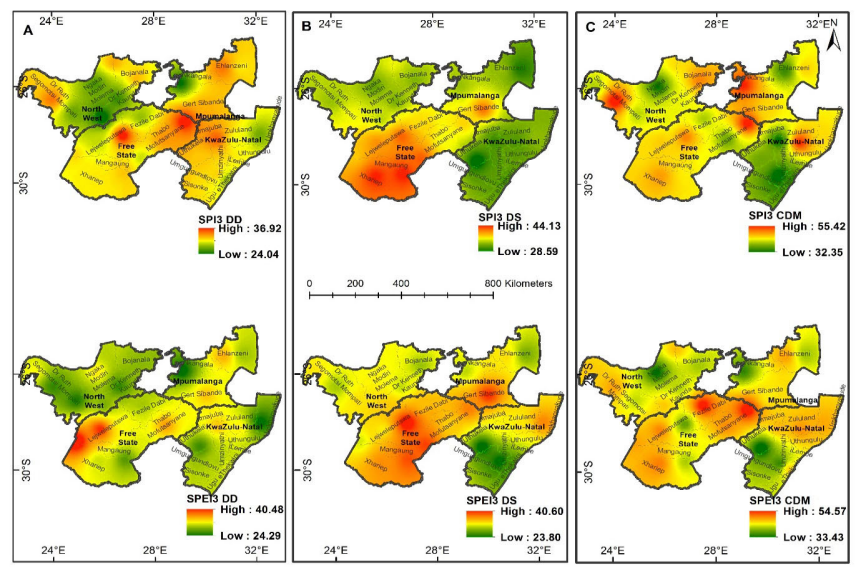

Fig. 10. Spatial contrasts of the coefficient of variation (CV) of DMIs derived from SPI-3 (top) and SPEI-3 (bottom): Panel A corresponds to DD while B and C correspond to DS and CDM.

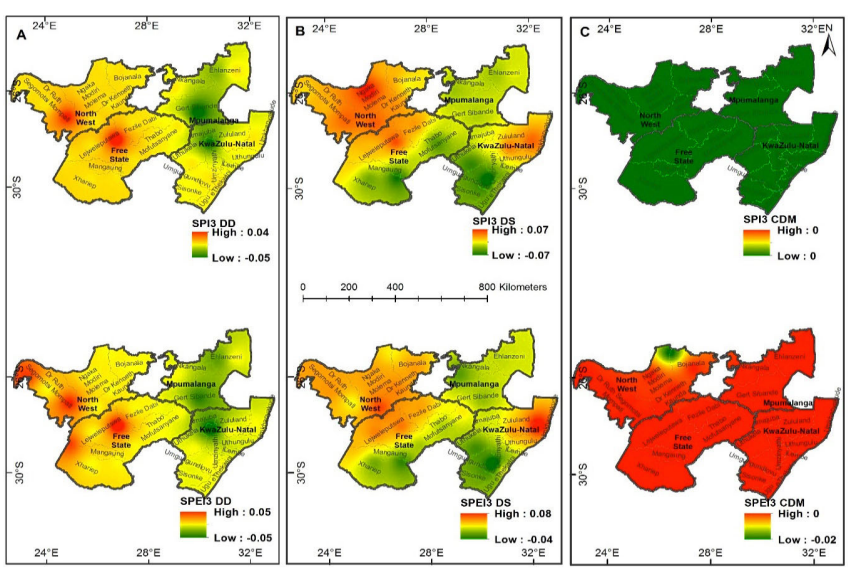

Fig. 11. Spatial contrasts of the trends of DMIs derived from SPI-3 (top) and SPEI-3 (bottom): Panel A corresponds to DD while B and $\mathrm{C}$ correspond to DS and CDM.

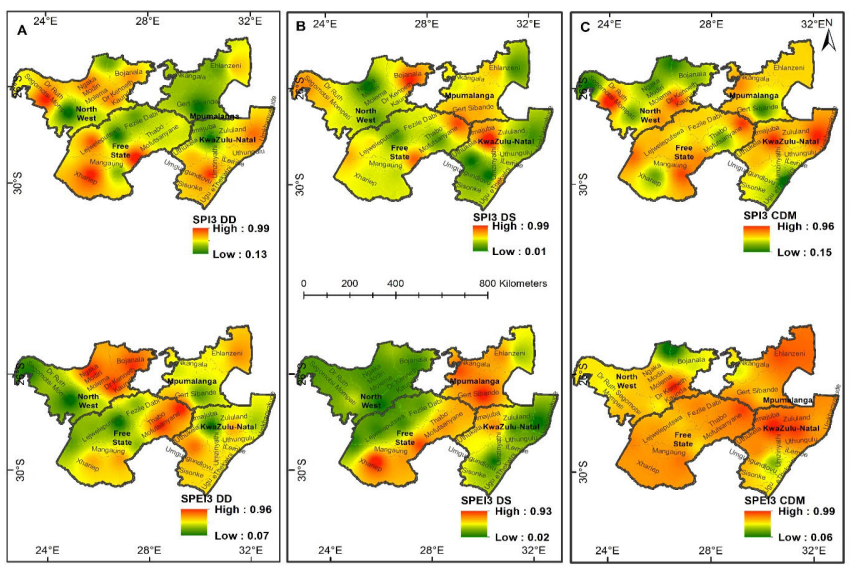

Fig. 12. Spatial contrasts of the p-values of DMIs derived from SPI-3 (top) and SPEI-3 (bottom): Panel A corresponds to DD while $\mathrm{B}$ and $\mathrm{C}$ correspond to DS and CDM. 


\subsection{Impacts of drought on the maize yield}

Table 3 shows the results of the correlation analysis between drought indices and maize yield across the provinces. The highest correlation was observed between the SPEI-3 and maize yield across all the provinces except for KZN where the SPI-3 has the highest correlation.

The correlation results given in Table 3 suggest that SPEI-3 is the most sensitive drought indicator to maize yield having correlation $(r=0.69,0.62,0.58 ; p<0.05$ in NW, FS and MP respectively) and SPI-3 $(r=0.67, p<0.05)$ in KZN. The results further indicate that the SPEI-3 is able to explain about $48 \%$, $39 \%$ and $34 \%$ of maize yield variation in NW, FS, and MP respectively, while the SPI-3 is able to explain about $45 \%$ of the variation in maize yield in KZN. The results suggest that the SPEI, which takes PET into account, can better estimate the impact of drought on maize yield in MP, FS, and NW while the SPI shows a better evaluation of the impact of drought on maize yield in KZN. These results are consistent with the findings of Zipper et al. (2016) and Kurniasih and Impron (2017) who reported that crops yield such as maize and soybean are most responsive to short-term (1-3 month) period. Similarly, Bachmair et al. (2018) reported that the SPI-3-month timescale was best suited for monitoring the effects of drought in agriculture and forestry. Furthermore, the results are also consistent with previous studies by Adisa et al. (2018) where result of the Partial Least Square Path Modeling (PLS-PM) analysis indicated that the impact of climatic elements on phenological parameters and indirectly on maize yield varies across the provinces with $70 \%$, $72 \%, 76 \%$ and $79 \%$ in Mpumalanga, KwaZulu-Natal, North West and Free State, respectively. The SPI-3 and SPEI-3 correspond with the critical reproductive stages of maize growing season (December-January) during silking and grain-filling (Aslam et $a l ., 2013)$. Drought occurrence during this stage could reduce the potential maize yield by up to $50 \%$ (Heiniger, 2001).

\section{Discussion}

For the effective policy support, social capital provision and adaptation of agricultural systems to climate change, it is essential to understand the impact of extreme climate conditions such as drought on agricultural production (Chen et al., 2014). In this study, two commonly used drought indices; SPI and SPEI were analyzed at different timescales of 1-, 3-, 6- and 12-month in order to determine their relationship with changes in maize yield. The results depict large spatial variations in drought impacts in term of its duration, frequency and severity and the trend, with drought associated with an average of $35 \%$ of the variation in maize yield. Drought at 3-month timescale (particularly, December-January, a critical reproductive stage of the growing season) tends to be the dominant driver of maize yield variability. The reproductive stages are the most sensitive stages of maize, hence the duration and severity of drought during this stage can reduce the potential maize yield by up to 50\% (Adisa et al., 2018). The results confirm previous findings that drought at short timescales is more significant than longer timescale because the growth and performance of crop are more sensitive to short-term weather events that alter soil moisture conditions rapidly and substantially (Wu et al., 2004). In this study, the SPI, a precipitation-based drought index, exhibits a lower correlation with maize yield across the provinces except in KZN. In addition, the SPEI estimates the drought-induced yield impact better than the SPI in warming weather conditions. The multi-scalar characteristics of SPEI enable it to identify different drought types and effects in the context of global warming (Ujeneza and Abiodun, 2015; Vicente-Serrano et al., 2010).

Furthermore, the variation in the duration, frequency, and severity of the SPI and SPEI indices can be explained by the variation in the climate characteristics across the provinces. As reported by the previous studies (e.g. Kruger and Nxumalo, 2017; Adisa et al., 2017; Botai et al., 2018), there is a large variation in the amount of rainfall received across the province. The north-eastern part of the country is often drier than the central, while the south-western part gets wetter. Furthermore, Kruger and Nxumalo (2017) reported that there is less amount of rainfall at the onset of rainfall, particularly in the FS province. Hence, drought conditions are more inherent in the northern (MP) and western-central (FS and NW) of the country. This could further explain the moderate drought observed in the FS province and extreme drought in the NW province during the vegetative stage. According to Das (2012), the intra-seasonal variability of rainfall could lead to a deficit in the uptake of the required amount of water by crops as a result of the reduction of moisture in the root zone.

\section{Conclusions}

This study analyzed the SPI and SPEI indices at 1-, 3-, 6- and 12-month timescales in order to characterize the variability of drought duration, severity and magnitude as well as to determine the index and time period that is more sensitive to maize yield fluctuations over the four major maize producing provinces of South Africa during the crop growing period. Upon analyzing the characteristics of the drought and their correlations to maize yield between 1990 and 2015, the following conclusions emerge from this study:

- Both the SPI and SPEI have the capacity to described drought severity, duration and intensity in the study area.

- Compared to other accumulation periods, SPEI-3 has the greatest influence on the variation in maize yield across the study area.

- Drought conditions epochs between 1990 and 2015 exhibit a clear spatial-temporal dependence structure which manifests in the overall marginal maize production.

- Drought impacts on maize yield depend on drought magnitude and duration and on plant growth stages when droughts occur. Drought events during maize reproductive and vegetative stages cause the highest reduction in maize yield.

- The reduced maize yield during the notable drought years (1991/92, 1994/95, 2002/03, 2004/05, 2006/07, 2008/09, 2009/10, 2011/12 and 2014/15) could be attributed to the low rainfall amount during the growing season in some parts of the NW province.

- There were persistent drought conditions occurring during the sensitive growing stages of maize in some parts of KZN and MP provinces. 
Overall, the present study contributes to the theoretical body of knowledge on droughts especially under changing climate. Results of this work could contribute towards the design of drought preparedness plans in a bid to manage future anticipated drought impacts in South Africa. One important area that the Agrometeorology community need to carefully consider is whether the salient features of the Fourth Industrial Revolution have been harnessed at the appropriate level and pace given that the drought conditions and other weather and climate extremes are a threat to food security, the economies as well as the society. For further studies, the social aspect should be included so as to access the effect of drought on the economy of the farmers. Also, research of drought impact on maize production at farm level is highly recommended. The lack of the social aspect and data at the farm level are limitations but will be ideal for future studies in order to develop an effective climate mitigation and adaptation strategies.

\section{Acknowledgments}

The authors gratefully acknowledge financial support from the Department of Science and Technology (DST) and The National Research Foundation (NRF).

\section{References}

Adisa OM, Botai CM, Botai JO, Hassen A, Darkey D, Tesfamariam E, Adisa AF, Adeola AM, Ncongwane KP, 2017: Analysis of agro-climatic parameters and their influence on maize production in South Africa. Theoretical and Applied Climatology 134, 991-1004.

Adisa OM, Botai JO, Hassen A, Darkey D, Adeola AM, Tesfamariam E, Botai CM, Adisa AT, 2018: Variability of satellite-derived phenological parameters across maize producing areas of South Africa. Sustainability 10, 3033; Doi: 10.3390/su10093033

Ali MG, Younes K, Esmaeil A, Fatemeh T, 2011: Assessment of geostatistical methods for spatial analysis of SPI and EDI drought indices. World Applied Sciences Journal 15, 474-482.

Allen RG, Pereira LS, Raes D, Smith M, 1998: Crop Evapotranspiration: Guidelines for Computing Crop Requirements, Irrigation and Drainage Paper 56, Roma, Italia: FAO.

Aslam M, Zamir MSI, Afzai I, Yaseen M, Mubeen M, Shoaib A, 2013: Drought stress, its effect on maize production and development of drought tolerance through potassium application. Agronomical Research in Moldavia 2, 99-114.

Bachmair S, Tanguy M, Hannaford J, Stahl K, 2018: How well do meteorological indicators represent agricultural and forest drought across Europe? Environmental Research Letters 13, 34-42.

Beguería S, Vicente-Serrano SM, 2013: SPEI: Calculation of the standardised precipitation-evapotranspiration index. R package. Available online: https://CRAN.R-project.org/package=SPEI (accessed on 1 May 2018).

Botai CM, Botai JO, Adeola AM, 2018: Spatial distribution of temporal precipitation contrasts in South Africa. South African Journal of Science 114, 1-9.

Botai CM, Botai JO, de Wit JC, Ncongwane KP, Adeola AM, 2017: Drought characteristics over the Western Cape Province, South Africa. Water 9, Doi: 10.3390/w9110876

Botai CM, Botai JO, Dlamini LC, Zwane NS, Phaduli E,
2016: Characteristics of droughts in South Africa: A case study of Free State and North West Provinces. Water 8, Doi: $10.3390 /$ w8100439

Byun H, Wilhite DA, 1999: Objective quantification of drought severity and duration. Journal of Climate 12, 2747-2756.

Ceglar B, Medved-Cvikl E, Moran-Tejeda S, Vicente-Serrano L, Kajfež-Bogataj, 2012: Assessment of multi-scale drought datasets to quantify drought severity and impacts in agriculture: a case study for Slovenia. International Journal of Spatial Data Infrastructures Research 7, 464-487.

Chen H, Fan L, Wu W, Liu HB, 2017: Comparison of spatial interpolation methods for soil moisture and its application for monitoring drought. Environmental Monitoring and Assessment 189: 525, Doi: 10.1007/s10661-017-6244-4

Chen H, Wang J, Huang J, 2014: Policy support, social capital, and farmers' adaptation to drought in China. Global Environmental Change 24, 193-202.

Chen T, van der Werf GR, de Jeu RAM, Wang G, Dolman AJ, 2013: A global analysis of the impact of drought on net primary productivity. Hydrology and Earth System Sciences 17, 3885-3894.

Chen T, Xia G, Liu T, Chen W, Chi D, 2016: Assessment of drought impact on main cereal crops using a standardized precipitation evapotranspiration index in Liaoning Province, China, Sustainability 8, 1069, Doi: 10.3390/su8101069

Dalezios N, Blanta A, Spyropoulos N, Tarquis A, 2014: Risk identification of agricultural drought for sustainable agroecosystems. Natural Hazards and Earth system Science 14, 2435-2448.

Das HP, 2012: Agrometeorology in extreme events and natural disasters. BS Publications, India, pp 600.

DAFF (Department of Agriculture, Forestry and Fisheries). Trends in the Agricultural Sector 2017. Pretoria. Available online: https://www.daff.gov.za/Daffweb3/Portals/0/ Statistics $\% 20$ and $\% 20$ Economic\%20Analysis/Statistical $\% 20$ Information/Trends $\% 20 \mathrm{in} \% 20$ the $\% 20$ Agricultural $\% 20$ Sector\%202017.pdf (Accessed 29 May 2018).

Dutta D, Kundu A, Patel NR, Saha SK, Siddiqui AR, 2015: Assessment of agricultural drought in Rajasthan (India) using remote sensing derived vegetation condition index (VCI) and Standardized Precipitation Index (SPI). The Egyptian Journal of Remote Sensing and Space Sciences 18, 53-63.

Edossa DC, Woyessa YE, Welderufael WA, 2014: Analysis of droughts in the central region of South Africa and their association with SST anomalies. International Journal of Atmospheric Sciences 2014, 1-8.

Grayson M, 2013: Agriculture and drought. Nature 501, S1, Doi: $10.1038 / 501 \mathrm{~S} 1 \mathrm{a}$

Heiniger RW, 2001: The impact of early drought on corn yield. 2001, Available at http://www.agrigold.com/Universal/ Articles/The-Effects-on-Drought-on-Corn-Yield/ (Accessed 11 June 2018).

Hollinger SE, Isard SA, Welford MR, 1993: A new soil moisture drought index for predicting crop yields. In proceedings of the 8th conference on applied climatology. Anaheim, CA, USA, 17-22 January, pp. 187-190.

Kruger AC, Nxumalo MP, 2017: Historical rainfall trends in South Africa: 1921-2015. Water South Africa 43, 285-297.

Kurniasih E, Impron P, 2017: Use of drought index and crop modelling for drought impacts analysis on maize (Zea mays L.) yield loss in Bandung district. IOP Conf. Series: Earth and Environmental Science 58, 12-36. 
Mansouri DMR, Bagherzadeh A, Khosravi M, 2013: Assessment of drought hazard impact on wheat cultivation using standardized precipitation index in Iran. Arabian Journal of Geosciences 11, 4463-4473.

Marchetto A, 2017: rkt: Mann-Kendall test, seasonal and regional kendall tests. Available online: https://CRAN.R-project.org/package=rkt (accessed on 1 May 2018).

Masupha TE, Moeletsi ME, 2017: Use of standardized precipitation evapotranspiration index to investigate drought relative to maize, in the Luvuvhu River catchment area, South Africa. Physics and Chemistry of the Earth, Parts A/B/C. 92, 1-9.

McKee TB, Doesken NJ, Kleist J, 1993: The relationship of drought frequency and duration to time scales. In proceedings of the 8th conference on applied climatology, Anaheim, CA, USA, 17-22 January, pp. 179-184.

Meroni M, Rembold F, Fasbender D, Vrieling A, 2017: Evaluation of the standardized precipitation index as an early predictor of seasonal vegetation production anomalies in the Sahel, Remote Sensing Letters 8, 301-310, Doi: 10.1080/2150704X.2016.1264020

Morid S, Smakhtin V, Moghaddasi M, 2006: Comparison of seven meteorological indices for drought monitoring in Iran. International Journal of Climatology 26, 971-985.

Palmer WC, 1968: Keeping track of crop moisture conditions, nationwide: the new crop moisture index. Weatherwise 21, 156-161.

Potop V, Možný M, Soukup J, 2012: Drought at various time scales in the lowland regions and their impact on vegetable crops in the Czech Republic. Agricultural and Forest Meteorology 156, 121-133.

Potop V, Boroneat C, Možný M, Štěpánek P, Skalák P, 2014: Observed spatio-temporal characteristics of drought on various time scales over the Czech Republic. Theoretical and Applied Climatology 112, 3-11.

Rhee J, Carbone GJ, Hussey J, 2008: Drought index mapping at different spatial units. Journal of Hydrometeorology $\mathbf{9}$, $1523-1534$.

Rouault M, Richard Y, 2003: Intensity and spatial extension of drought in South Africa at different time scales. Water South Africa 4, 489-500.

Thornthwaite CW, 1948: An approach toward a rational classification of climate. Geographical Review 38, 55-94.

Ujeneza EL, Abiodun BJ, 2015: Drought regimes in Southern
Africa and how well GCMs simulate them. Climate Dynamics 44, 1595-1609.

Vasiliades L, Loukas A, 2013: An operational drought monitoring system using spatial interpolation methods for Pinios river basin, Greece. Proceedings of the 13th International Conference on Environmental Science and Technology. Athens, Greece, 5-7 September 2013.

Vicente-Serrano SM, Beguería S, López-Moreno JI, 2010: A multiscalar drought index sensitive to global warming: The standardized precipitation evapotranspiration index. Journal of Climate 23, 1696-1718.

Vicente-Serrano SM, Beguería S, Lorenzo-Lacruz J, Camarero JJ, López-Moreno JI, Azorin-Molina C, Revuelto J, Morán-Tejeda E, Sanchez-Lorenzo A, 2012: Performance of drought indices for ecological, agricultural, and hydrological applications. Earth Interactions 16, 1-27.

Vicente-Serrano SM, Sergio M, and National Center for Atmospheric Research Staff, 2015: The climate data guide: standardized precipitation evapotranspiration index (SPEI). Available at: https://climatedataguide.ucar.edu/climatedata/sta ndardizedprecipitationevapotranspiration-index-spei (Accessed on 15 April 2016).

Vogel C, Laing M, Monnik K, 2000: Drought in South Africa, with spatial reference to the 1980-94 period. In Drought: A Global Assessment (ed. by Wilhite DA). Routledge, England pp. 348-366.

Wilhite DA, 2000: Drought: A Global Assessment. Routledge, New York, 1, 89-104.

Woli P, Jones J, Ingram K, Paz J, 2013: Forecasting drought using the agricultural reference index for drought (arid): A case study. Weather and Forecasting 28, 427-443.

Wu H, Hubbard KG, Wilhite DA, 2004: An agricultural drought risk-assessment model for corn and soybeans. International Journal of Climatology 24, 723-741.

Yue S, Pilon P, Phinney B, Cavadias G, 2002: The influence of autocorrelation on the ability to detect trend in hydrological series. Hydrological Processes 16, 1807-1829.

Zhang Q, Zhang J, 2016: Drought hazard assessment in typical corn cultivated areas of China at present and potential climate change. Natural Hazards 81, 1323-1331.

Zipper CS, Qiu J, Kucharik JC, 2016: Drought effects on US maize and soybean production: spatiotemporal patterns and historical changes. Environmental Research Letters 11, Doi: $10.1088 / 1748-9326 / 11 / 9 / 094021$ 